\title{
Apicultura na Educação Infantil: Interagindo com as abelhas para conhecer, preservar e consumir
}

\author{
Beekeeping in Childhood Education: Interacting with bees to know, preserve and consume \\ La apicultura en la Educación Infantil: Interactuar con las abejas para conocer, conservar y \\ consumir
}

Recebido: 11/07/2021 | Revisado: 16/07/2021 | Aceito: 27/07/2021 | Publicado: 03/08/2021

\author{
Kécia Martins Bastos \\ ORCID: https://orcid.org/0000-0003-0020-6968 \\ Universidade Federal de São João del-Rei, Brasil \\ E-mail: kecia.bastos@gmail.com \\ Renata Rocha Rebouças \\ ORCID: https://orcid.org/0000-0002-8363-1208 \\ Universidade Federal de São João del-Rei, Brasil \\ E-mail: renatarreboucas27@gmail.com \\ Márcia Jorge do Carmo \\ ORCID: https://orcid.org/0000-0002-5030-0250 \\ Universidade Federal de São João del-Rei, Brasil \\ E-mail: mrcarmo16@gmail.com \\ Mateus Henrique Reis Coelho \\ ORCID: https://orcid.org/0000-0002-8132-4669 \\ Universidade Federal de São João del-Rei, Brasil \\ E-mail: mateus-hrc@hotmail.com \\ Bianca Magalhães \\ ORCID: https://orcid.org/0000-0001-7601-5178 \\ Universidade Federal de São João del-Rei, Brasil \\ E-mail: bimagalhaes@outlook.com \\ Deodoro Magno Brighenti \\ ORCID: https://orcid.org/0000-0002-0612-1802 \\ Universidade Federal de São João del-Rei, Brasil \\ E-mail: deodoro@ufsj.edu.br \\ Carla Regina Guimarães Brighenti \\ ORCID: https://orcid.org/0000-0002-7822-3744 \\ Universidade Federal de São João del-Rei, Brasil \\ E-mail: carlabrighenti@ufsj.edu.br
}

\begin{abstract}
Resumo
O projeto Apicultura na educação infantil: Interagindo com as abelhas para conhecer, preservar e consumir foi implantado no ano de 2019 nas dependências do Campus Tancredo de Almeida Neves (CTAN) na Universidade Federal de São João del-Rei (UFSJ). A promoção de conhecimento sobre a diversidade das espécies de abelhas (melipona - abelhas sem ferrão ou melífera - abelha com ferrão), atividades apícolas, seus produtos e a interação das abelhas com o meio ambiente, teve o intuito de despertar o interesse das crianças para a preservação de colônias, a valorização de produtos apícolas, e maior aceitação da implementação do mel nas merendas escolares. Ao fim do primeiro ano da realização do projeto, os primeiros reflexos do trabalho realizado foram notados: duas escolas participantes do projeto solicitaram junto à prefeitura, a demanda de 3.000 sachês de mel para chamada pública através do Programa Nacional de Alimentação Escolar (PNAE), para aquisição de gêneros alimentícios da Agricultura Familiar, para alimentação escolar.
\end{abstract}

Palavras-chave: Abelha sem ferrão; Abelha; Trilha ecológica; Educação ambiental; Melípona; Melífera.

\begin{abstract}
The Apiculture project in early childhood education: Interacting with bees to know, preserve and consume was implemented in 2019 on the premises of the Tancredo de Almeida Neves Campus (CTAN) at the Federal University of São João del-Rei (UFSJ). The promotion of knowledge about the diversity of bee species (melipona - stingless bees or honeybee - stinging bee), beekeeping activities, their products and the interaction of bees with the environment, aims to arouse children's interest in the preservation of colonies, the valorization of bee products, and greater acceptance of the implementation of honey in school lunches. At the end of the first year of the project's realization, the first reflections of the work carried out were noted: two schools participating in the project requested from the city government the demand for 3,000 honey sachets for public calls through the National School Feeding Program (PNAE), for the acquisition of foodstuffs from Family Farming, for school feeding.
\end{abstract}

Keywords: Stingless bee; Bee; Ecological trail; Environmental education; Melipona; Honeybee. 


\section{Resumen}

El proyecto Apicultura en la educación infantil: Interactuar con las abejas para conocer, preservar y consumir se implementó en 2019 en las instalaciones del Campus Tancredo de Almeida Neves (CTAN) de la Universidad Federal de São João del-Rei (UFSJ). La promoción del conocimiento sobre la diversidad de especies de abejas (melipona abejas sin aguijón o abeja melífera - abeja picadora), las actividades apícolas, sus productos y la interacción de las abejas con el medio, tiene como objetivo despertar el interés de los niños por la preservación de colonias, la valorización de productos apícolas, y mayor aceptación de la implementación de la miel en los almuerzos escolares. Al finalizar el primer año de realización del proyecto, se notaron las primeras reflexiones del trabajo realizado: dos escuelas participantes del proyecto solicitaron al gobierno de la ciudad la demanda de 3.000 bolsitas de miel para convocatorias públicas a través del Programa Nacional de Alimentación Escolar (PNAE), para la adquisición de alimentos de la Agricultura Familiar, para la alimentación escolar.

Palabras clave: Abeja sin aguijón; Abeja; Sendero ecológico; Educación ambiental; Melipona; Abeja.

\section{Introdução}

Nas últimas décadas, várias pesquisas têm demonstrado que os primeiros seis à dez anos de vida de uma criança se constituem em período de intenso aprendizado e desenvolvimento, em que se assentam as bases do "aprender a conhecer", “aprender a viver junto", "aprender a fazer" e "aprender a ser" (Unesco, 2018). O atendimento educacional de qualidade, nessa fase da vida, tem um impacto extremamente positivo no curto, médio e longo prazo, gerando benefícios educacionais, sociais e econômicos mais expressivos do que qualquer outro investimento na área social.

Considerando a atividade da criança no trabalho com projetos, a importância dessa prática na sua aprendizagem e desenvolvimento, o projeto "Apicultura na educação infantill" veio atuar nessa fase da educação infantil, pois se trata de uma oportunidade promissora para formação e propagação de ideias. Isso torna possível conectar dois pontos: auxiliar na formação de crianças acerca da importância da preservação das abelhas e do meio ambiente, e ainda instigar esses mesmos alunos para uma maior aceitação da implementação do mel no âmbito escolar, a fim de despertar a curiosidade e o interesse de consumo.

Abrir espaço para inserção do mel no cardápio das merendas através da inserção dos apicultores de São João del-Rei no Programa Nacional de Alimentação Escolar (PNAE) favorece toda a cadeia produtora do mel, o número de pessoas envolvidas na atividade (mantém ou estimula o crescimento) e consequentemente ações que também vão de encontro com o intuito de preservar a vida das abelhas.

O Programa Nacional de Alimentação Escolar (PNAE) foi criado em 1979, mas somente com a promulgação da Constituição Cidadã em 1988, foi assegurado o direito à alimentação escolar a todos os alunos do ensino fundamental, como programa suplementar à política educacional. Em 1993, inicia-se o processo de descentralização dos recursos financeiros destinados ao PNAE para os estados e municípios com o intuito de aperfeiçoar o desempenho; introduzir mudanças na sistemática de compras; implantar a produção alternativa de alimentos; e utilizar produtos básicos in natura e semielaborados da localidade, o que permitiu melhorar a aceitabilidade das refeições e diversificar os cardápios (Abreu, 1996).

Em 16 de junho de 2009 foi sancionado o Programa Nacional de Alimentação Escolar (PNAE) e dispõe sobre a utilização de, no mínimo, 30\% dos recursos repassados pelo Fundo Nacional de Desenvolvimento da Educação (FNDE) para alimentação escolar, na compra de produtos da agricultura familiar e do empreendedor familiar rural ou de suas organizações, priorizando os assentamentos de reforma agrária, as comunidades tradicionais indígenas e comunidades quilombolas, de acordo com o Artigo 14 (Brasil, 2020). A Lei define a alimentação escolar como um direito humano e incorpora dimensões estratégicas para a promoção da soberania e segurança alimentar e nutricional dos escolares com a valorização da cultura alimentar e da produção local, inclusão da educação alimentar e nutricional no projeto pedagógico da escola, promoção da saúde do escolar e fortalecimento da agricultura familiar (Ribeiro, 2013).

Triches e Schneider (2010) avaliam que o PNAE, após a Lei n¹1.947, passou a apresentar um grande potencial para tornar-se uma política de caráter estruturante, ao abrir a possibilidade de adquirir os gêneros alimentícios de produtores locais, gerando renda e beneficiando pequenos agricultores e comerciantes. 
O projeto Apicultura na educação infantil: Interagindo com as abelhas para conhecer, preservar e consumir foi implantado no ano de 2019 nas dependências do Campus Tancredo de Almeida Neves (CTAN) na Universidade Federal de São João del-Rei (UFSJ). Tem se mantido desde então devido ao grande êxito em sua realização, com o propósito de propagar a importância das abelhas tanto para atividade econômica local, quanto para educação ambiental na região.

A promoção de conhecimento sobre a diversidade das espécies de abelhas (meliponas - abelhas sem ferrão ou melífera - abelha com ferrão), atividades apícolas, seus produtos e a interação das abelhas com o meio ambiente, têm o intuito de despertar o interesse das crianças para a preservação de colmeias, a valorização de produtos apícolas, e maior aceitação da implementação do mel nas merendas escolares.

Com isso, a inserção do mel provindo de agricultura familiar no cardápio das merendas escolares por meio do Programa Nacional de Alimentação Escolar (PNAE), contempla apicultores que também contribuem para a preservação das abelhas em suas atividades apícolas.

No projeto foram realizadas várias atividades, subdivididas em etapas, para facilitar o aprofundamento de alguns aspectos expostos aos visitantes. São elas: verificação dos conhecimentos prévios dos alunos acerca do tema; palestra sobre abelhas sem ferrão e africanizadas; exibição de um curto filme; condução na Trilha Ecológica; interação e recreação no lanche partilhado entre os alunos visitantes; visitas com os alunos no meliponário didático-experimental; além da temática referente à importância da preservação da natureza, que é discutida durante o percurso, onde pode-se observar as colmeias nidificadas em ninhos aéreos e subterrâneos dispersos de forma natural pela trilha.

\section{Metodologia}

Apresenta-se a seguir a metodologia da pesquisa em quatro subtítulos que descrevem os percursos metodológicos incluindo a natureza e o tipo de pesquisa, contexto do estudo, definição do local, os instrumentos de seleção de participantes.

\subsection{Natureza e Tipo de Pesquisa}

Trata-se de uma pesquisa na área de Educação Ambiental de natureza qualitativa do tipo pesquisa-ação, pois, de acordo com Ludke e André (1986), “[...] a pesquisa qualitativa supõe o contato direto e prolongado do pesquisador com o ambiente e a situação que está sendo investigada, via de regra através do trabalho de intensivo de campo [...]”. E, a pesquisaação é definida, por Thiollent (2005), como uma metodologia derivada da pesquisa social com base empírica, concebida e realizada em estreita associação com uma ação ou a resolução de um problema coletivo, e na qual pesquisadores e participantes representativos da situação ou problema estão envolvidos de modo cooperativo ou participativo. Nesta pesquisaação buscou-se refletir sobre a importância da preservação das espécies de abelhas nativas (abelhas-sem-ferrão), especialmente com alunos do Ensino Fundamental, bem como sobre as ações para identificação e preservação das abelhas bem como o consumo de derivados apícolas, possibilitando o envolvimento e a participação dos sujeitos da pesquisa.

\subsection{Contexto do Estudo}

Considerando a atividade da criança no trabalho com projetos, e a importância dessa prática na sua aprendizagem e desenvolvimento, o Grupo de Estudos em Apicultura e Meliponicultura GEAPIS vem realizando projetos na área de apicultura desde 2012. Entre eles o denominado "Apicultura na educação infantil: Interagindo com as abelhas para conhecer, preservar e consumir" teve como objetivo divulgar a preservação das espécies de abelhas nativas (abelhas sem ferrão), por meio de 
atividades com apresentação de slides, material apícola, produtos apícolas e observação dos ninhos de exemplares de abelhas sem ferrão.

Dentre as atividades inicialmente propostas pelo grupo contemplando ensino, pesquisa e extensão, surgiu a ideia de elaborar uma Trilha Ecológica para investigação das melíponas (abelhas-sem-ferrão) dispersas pelas dependências do Campus Tancredo Neves (CTAN) na Universidade Federal de São João del-Rei (UFSJ). A localização da trilha encontra-se em caminhos onde já ocorre a circulação de pessoas diariamente, áreas calçadas e áreas em terra. Eventualmente os ninhos das melíponas eram devastados ou destruídos pela desinformação de pessoas que circulavam nesses caminhos. Vista a oportunidade, o grupo GEAPIS com a intenção de promover a preservação das abelhas e proporcionar maior contato entre estudantes e abelhas em seu habitat, promoveu a visita de estudantes das escolas da região ao CTAN, para realização da Trilha Ecológica de melíponas.

\subsection{Definição do Percurso}

Após a inclusão da Trilha Ecológica no planejamento do grupo, a primeira ação foi mapear e identificar as espécies de abelhas sem ferrão. A identificação de cada espécie se deu através de consultas em bibliografias, analisando características do indivíduo, bem como as especificidades e características de seu ninho, levando assim a determinação e reconhecimento de cada espécie.

Foi traçado o percurso mais adequado para crianças, incluindo as etapas: (i) Recepção e apresentação sobre a vida e importância das abelhas no anfiteatro; (ii) Realização da trilha; (iii) Lanche compartilhado; (iv) Visita ao meliponário didáticoexperimental da UFSJ e Degustação de méis de abelhas.

\subsection{Instrumentos de Seleção de Participantes}

Com a trilha estabelecida para o recebimento de visitantes, começou-se o processo de divulgação para as escolas municipais, estaduais e privados da rede de ensino da cidade de São João del Rei - MG. Para tal finalidade realizou-se inicialmente uma pesquisa entre apicultores participantes da Associação Apis del Rei. Através de um questionário respondido pelos apicultores, foi levantado o nome das escolas onde as mais citadas foram convidadas a participar das atividades do projeto.

O questionário foi composto por duas perguntas: "Possui filhos, netos sobrinhos ou parentes com idade entre 4 a 15 anos de idade? "; "Se sim, o nome da escola em que estudam, idade ou turno (matutino/vespertino)".

Por meio do diálogo estabelecido com a direção de cada escola, foi possível conhecer a organização do calendário escolar, assim como a estruturação de conteúdos de professores, inclusive na disciplina de ciências e áreas afim, propondo então as atividades da pesquisa. Para concretizar a organização das visitas foram escolhidas as turmas que mais poderiam se beneficiar da proposta do projeto. A partir de então, os responsáveis pelos alunos em cada turma foram convocados para uma reunião de esclarecimentos, junto a direção escolar e participantes do projeto, para preenchimento de ficha com autorização para visita e declaração de impedimentos com relação a alimentação/alergias aos produtos apícolas.

\section{Resultados e Discussão}

\subsection{Trilha Ecológica das Meliponas}

Foram identificados 12 ninhos de abelhas sem ferrão na área mais central do campus. Dentre eles as principais espécies foram de Tetragonisca angustula (Jataí), Trigona spinipes (Cachorro ou Irapuá) e Geotrigona mombuca smith (Figura 1). 
Figura 1. Ninhos de Abelhas sem ferrão: (A) Tetragonisca angustula (Jataí), (B) Trigona spinipes (Cachorro ou Irapuá), (C) Geotrigona mombuca smith (Guira).

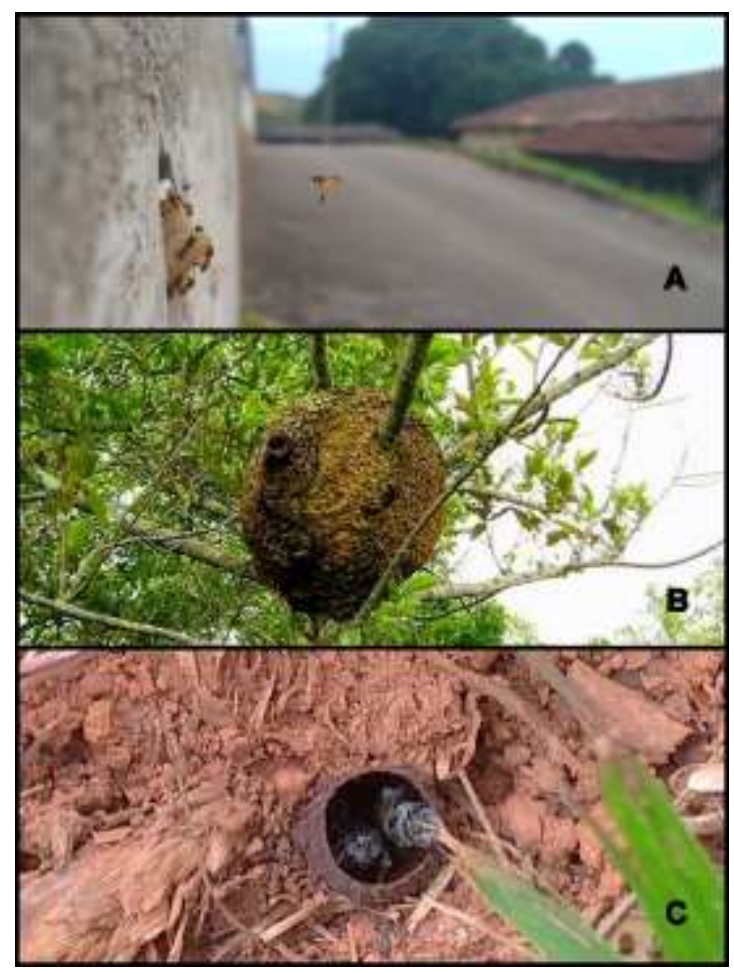

Fonte: Autores.

Para cada uma das espécies identificadas, foi realizada uma revisão de conteúdo capacitando cada monitor na condução do grupo de alunos ao longo da trilha, podendo explicar sobre características da espécie tais como tipo de ninho, distinção da entrada do ninho, comportamento defensivo, tamanho, coloração, hábitos de forrageamento entre outros pontos sobre o assunto. Algumas dessas principais especialidades para cada espécie estão apresentadas a seguir:

\section{Tetragonisca angustula (Figura $1 \mathrm{~A}$ )}

As abelhas indígenas, especialmente a T. angustula, popularmente conhecidas como Jataí, são criadas em praticamente todo território nacional, principalmente, pela ausência de defenssividade, o que facilita seu manejo, bem como pelo fato de produzirem um mel bastante apreciado e valorizado). A colônia de T. angustula pode chegar a conter 10.000 indivíduos (Gruter et al., 2011). Essas abelhas são de hábito higiênico, pois não pousam em esterco de animais, não coletam suor animal para a construção de ninhos ou misturar ao mel ou pólen. Além disso, o mel não necessita ser pasteurizado como o de outras espécies (Nogueira-Neto, 1997). Ecologicamente, esses polinizadores são considerados essenciais para a biodiversidade global (Giannini et al., 2012). Contudo, essa interação inseto-planta tem sido perturbada pela degradação, queimadas, desmatamento das florestas, uso indiscriminado de defensivos agrícolas, queimada e mesmo pela ação de apicultores desinformados em relação à espécie (Lautenbach et al., 2012). A abelha T. angustula tem facilidade em ocupar lugares variados para nidificação, tal fato influencia positivamente o sucesso evolutivo da espécie (Castanheira; Contel, 1995).

\section{Trigona spinipes (Figura 1 B)}

A abelha-cachorro ou Irapuá, T. spinipes (Hymenoptera: Apidae) são insetos sociais de colônias perenes com centenas a milhares de operárias. A abelha adulta apresenta coloração preta, mandíbulas desenvolvidas, asas transparentes, com ferrão 
atrofiado, portanto são chamadas de abelhas sem ferrão. Medem cerca de 5 a 7,5 mm de comprimento. Enrolam-se nos cabelos das pessoas quando perturbado (Zucchi et al.,1993). Constrói seus ninhos nas árvores, entre os ramos, ou em cupinzeiros arbóreos abandonados, empregando filamentos fibrosos de vegetais com elementos aglutinantes, compostos principalmente de resinas (Gallo et al., 1994). A colônia constituída de operárias, machos, uma rainha fecundada e rainhas virgens, larvas (em alvéolos fechados contendo mel, pólen e secreção glandular das operárias) e pupas. São observadas frequentemente visitando as flores do maracujazeiro. Dentre os meliponíneos ela é tida como uma das espécies mais defensivas (Gallo et al. 1988).

\section{Geotrigona mombuca (Figura 1 C)}

A abelha G. mombuca Smith, 1863, comumente conhecida como Guira, nidifica nos ninhos desocupados de formigas do gênero Atta (Nogueira-Neto, 1970; Lacerda et al., 1991). A entrada do ninho consiste em um tubo próximo ao solo, com cera escura, cercado por paus e torrões (Nogueira-Neto, 1970). Um ninho subterrâneo é comparativamente mais vulnerável do que os ninhos de abelhas sem ferrão (Meliponinae), que são mais difíceis de ver e localizar. Esses fatores podem explicar parcialmente a falta de estudos sobre essa espécie, uma vez que pouco se sabe além de sua descrição (Camargo \& Moure, 1996), distribuição geográfica (Camargo \& Pedro, 2013) e alguns aspectos da biologia intranidal (Lacerda et al., 1991).

Para cumprir o objetivo das trilhas ecológicas, oito estações (pontos de parada) foram definidas por meio de placas de identificação conforme cada espécie disposta no local, sendo três espécies de abelhas nativas. Como afirmam Costa et.al. (2012), as trilhas visam propiciar atividades que revelam os significados e as características do ambiente por meio de uso dos elementos originais, por experiência direta e por meios ilustrativos, encaixando-se como um instrumento básico de Educação Ambiental. Desta forma, a placa de identificação continha o nome popular, nome científico, principais características, curiosidades e imagem ilustrativa da referida espécie de abelha. Exemplos das placas de identificação afixadas nos pontos de parada estão da Figura 2.

Figura 2. Placas de identificação: (A) Trigona spinipes (abelha cachorro ou Irapuá), (B) Geotrigona mombuca smith (Guira), (C) Tetragonisca angustula (Jataí).

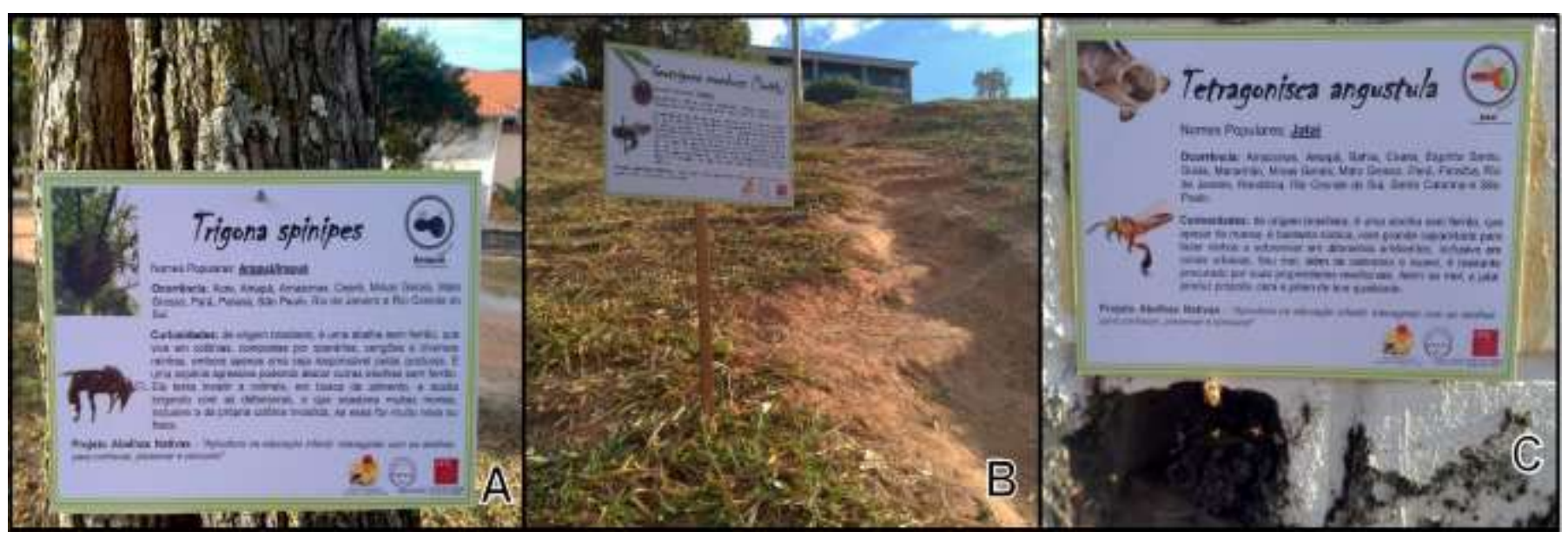

Fonte: Autores.

\subsection{Participantes}

Através do questionário realizado, foram selecionadas as onze escolas mais citadas. O número de escolas participantes foi definido de acordo com a disponibilidade de recursos do Fundo de Extensão da Pró-Reitoria de Extensão (PROEX) com transporte para buscar os estudantes nas escolas, possibilitando a vinda desses alunos até as dependências do CTAN, e ao fim 
das atividades retornar com os estudantes para a escola. As visitas foram programadas para sextas-feiras dos meses de agosto, setembro e outubro, sendo uma escola no turno matutino e outra escola no turno vespertino.

No Gráfico 1 está representado o número de alunos atendidos no ano de 2019, somando um total de 504 alunos participantes ao longo do ano. Os alunos mostraram-se satisfeitos com as atividades realizadas, sensibilizados expressando cuidado com as abelhas e com o ambiente durante e após as atividades de visitação. Todas as escolas participantes manifestaram interesse em participar novamente no ano seguinte, e novas escolas que tomaram conhecimento do projeto devido sua repercussão na região, entraram em contato para manifestar interesse.

Gráfico 1 - Número de alunos atendidos nas Escolas Participantes em 2019.

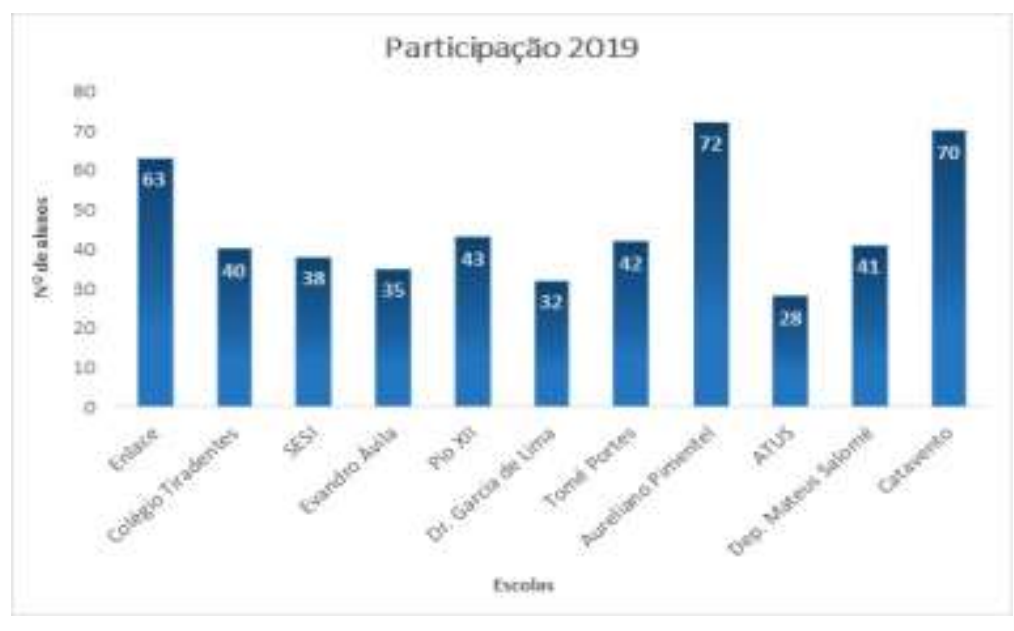

Fonte: Autores.

\subsection{Etapas da Realização da Visita das Escolas}

\section{Recepção e apresentação sobre a vida e importância das abelhas}

Os estudantes foram recepcionados pela equipe de monitores do projeto na entrada do Campus e conduzidos ao anfiteatro. Neste ambiente foi realizada uma conversa para verificar os conhecimentos prévios dos visitantes e explanar os seguintes tópicos fixos: para que servem as abelhas; abelhas e o meio ambiente; polinização; família das abelhas; identificação de abelhas; colheita do mel; o ferrão da abelha; abelhas sem ferrão. Além desses, outros tópicos eram discutidos conforme a discussão e curiosidades dos participantes. Dentre eles tópicos como alergia de abelhas, acasalamento, produção da própolis, produtos a base de cera de abelhas entre outros (Figura 3). Ao final foi exibido um filme de animação sobre a vida das abelhas. 
Figura 3. Recepção e conversa com os visitantes.

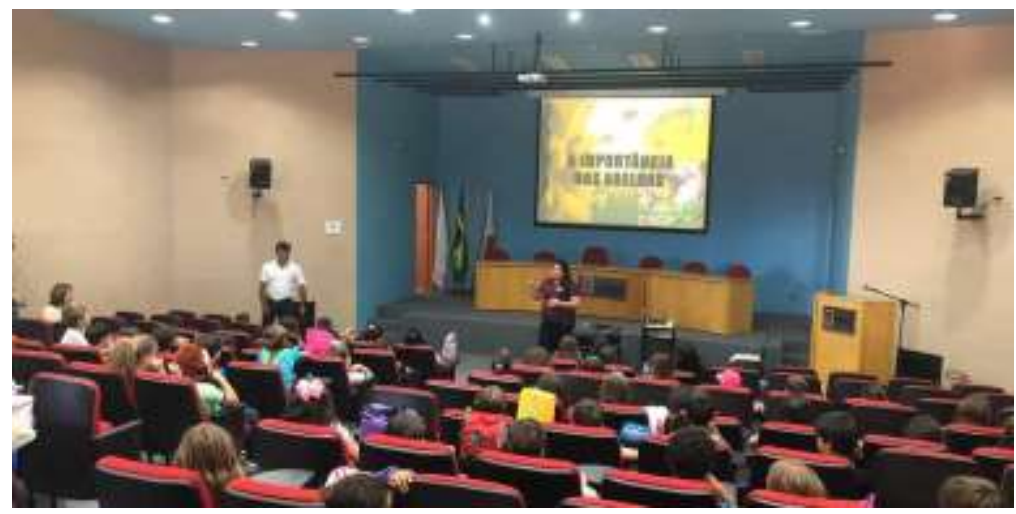

Fonte: Autores.

Assim, já não se abordavam temáticas descontextualizadas, mas sim pontos chaves importantes à compreensão do tema do projeto, da importância das abelhas e sua preservação, bem como da sua dinâmica comportamental auxiliando na caminhada da trilha.

\section{Realização da Trilha Ecológica}

Após a palestra sobre abelhas e exibição do filme os alunos foram então conduzidos em grupos de no máximo 8 participantes, distribuídos entre os monitores do grupo para realização da trilha. Foram definidos locais estratégicos de parada na trilha para melhor elucidar facilitar o entendimento dos visitantes às vertentes expostas. Lemes (2004) acrescenta que as trilhas devem explorar o raciocínio lógico, incentivar a capacidade de observação e reflexão, além de apresentar conceitos ecológicos e estimular a prática investigatória. Tal prática investigatória, muitas vezes manifestada pela curiosidade, foi aproveitada para gerar um sentimento de responsabilidade, pertencimento, conservação e preservação das abelhas, bem como de todas as áreas naturais (Figura 4).

Figura 4. Ponto de parada na Trilha Ecológica.

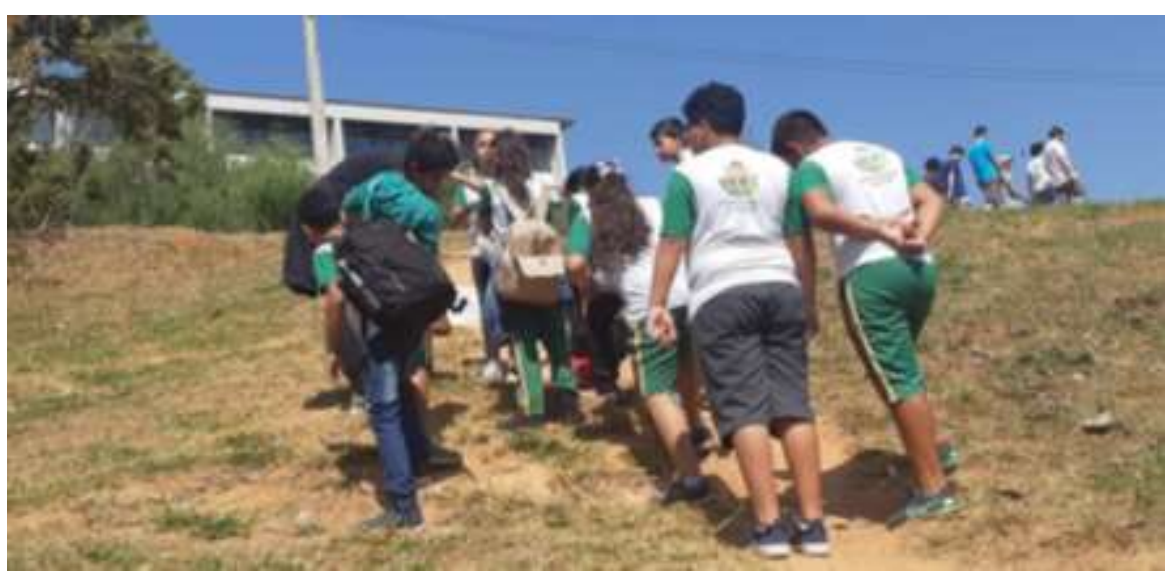

Fonte: Autores.

\section{Lanche compartilhado}

O ponto final da Trilha ecológica se dava no espaço direcionado ao lanche compartilhado. Muitas vezes eram inseridas outras atividades juntamente com a trilha, como um jogo de perguntas e respostas, adivinhação, e dinâmicas para despertar a concentração. Tudo isso realizado em um espaço amplo preparado para o momento onde ocorre a atividade 
denominada lanche compartilhado, onde os estudantes se reúnem em torno de toalhas estendidas na grama ou em mesas dispostas nas proximidades (Figura 5). Tais atividades contribuíram acrescentando informações de forma lúdica e captando, ainda mais, o interesse dos estudantes. Além disso, demais assuntos eventualmente não abordados na trilha, conforme os interesses dos alunos foram tratados neste momento.

Figura 5. Lanche compartilhado.

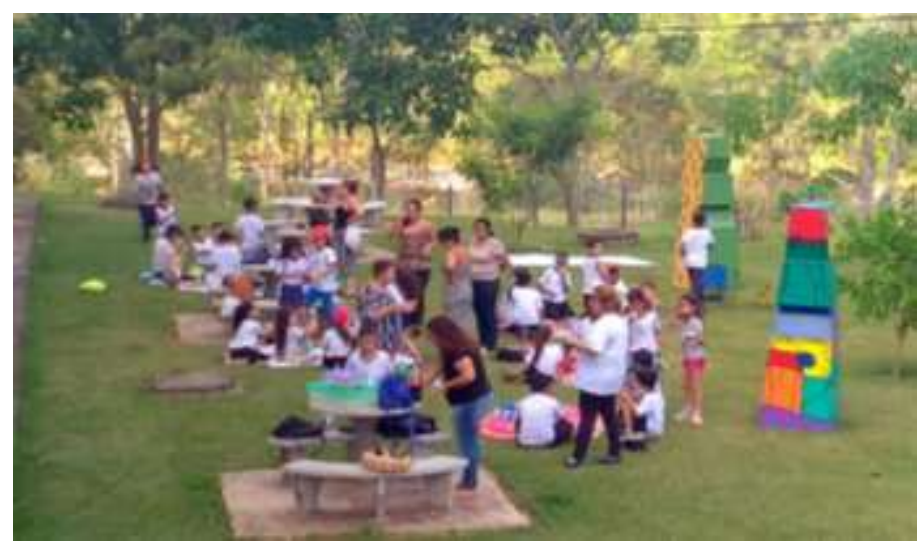

Fonte: Autores.

\section{Visita ao meliponário didático-experimental da UFSJ}

A última etapa do projeto é tida como aquela que alcançou o ápice das informações transmitidas ao longo de todo o projeto. A visita ao meliponário didático-experimental funciona como o termômetro de conhecimentos absorvidos, por meio de uma roda de conversa onde os estudantes novamente contribuem com perguntas e respostas acerca das espécies de meliponas dispersas de forma natural no campus, e de exemplares exibidos dos ninhos alocados em caixas (Figura 6). Por fim, os estudantes interessados realizavam a degustação facultativa dos méis de abelhas meliponas e também das abelhas africanizadas que eram apresentadas em núcleos expositores com segurança.

Figura 6. Roda de conversa meliponário.

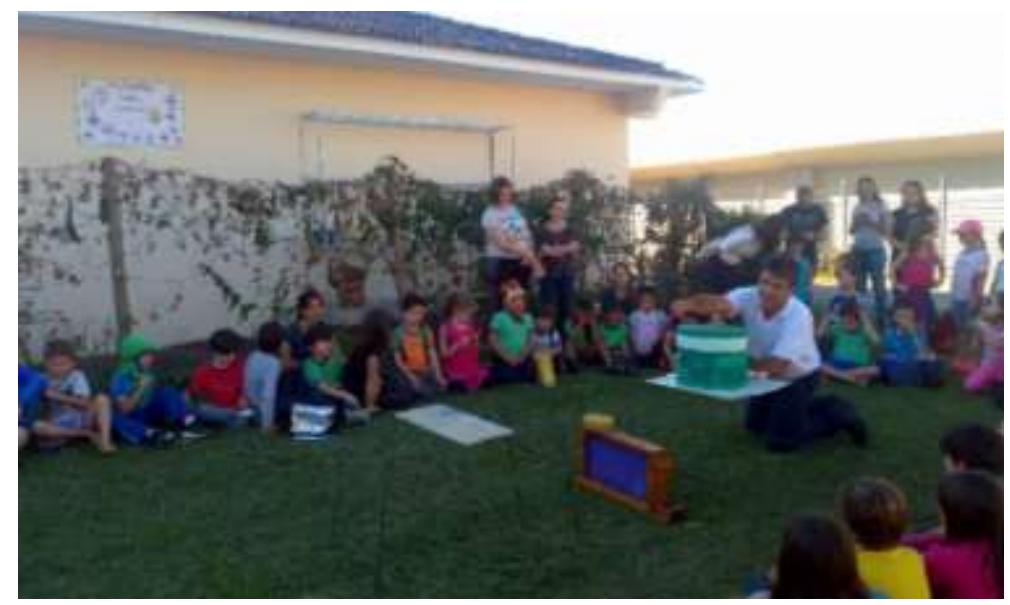

Fonte: Autores.

\section{Considerações Finais}

Através da realização do projeto conseguiu-se despertar o interesse das crianças para a preservação das abelhas, a valorização de produtos apícolas, e maior aceitação da implementação do mel nas merendas escolares. Com isso, a inserção do 
mel provindo de agricultura familiar no cardápio das merendas escolares por meio do Programa Nacional de Alimentação Escolar (PNAE) contempla apicultores que também contribuem para a preservação das colônias em suas atividades apícolas.

Em uma das primeiras reuniões da Associação Apis del Rei do ano de 2020, foi observado os primeiros reflexos do trabalho realizado com o projeto apicultura na educação infantil: duas escolas participantes do projeto solicitaram junto à prefeitura, a demanda de 3.000 sachês de mel para chamada pública através do Programa Nacional de Alimentação Escolar (PNAE), para aquisição de gêneros alimentícios da Agricultura Familiar, para alimentação escolar.

É de necessidade o fomento ao desenvolvimento da sensibilização das pessoas, individual e coletivamente, em relação ao tema, que abranja e considere a concepção do princípio da preservação, em que atitudes e valores no que se refere à vida das abelhas possam ser trabalhados favorecendo então a preservação das abelhas juntamente com o meio ambiente, e fortalecendo o lado socioeconômico da população pertencente à Agricultura Familiar.

Ressalta-se que a lei 11947 trata sobre a aquisição de produtos da Agricultura Familiar para alimentação escolar, destacando que deve ser utilizado o mínimo de 30\% dos recursos originados do Fundo Nacional de Desenvolvimento Escolar exclusivamente para este fim. E essa lei é de suma importância na política de segurança alimentar, nutricional, permitindo uma alimentação saudável nas escolas e em consequência a diminuição do êxodo rural e aumento na renda dos agricultores. Contudo, o projeto em estudo permitiu visualizar a fragilidade desta política pública em que, apesar da existência de apicultores e associação apícola na região, o mel não chega de modo efetivo na merenda escolar. Tal fato ressalta a necessidade de continuidade de projetos de tal natureza, sendo que há ainda fragilidade na participação dos agricultores familiares em licitações públicas. É interessante incentivar novos projetos que visem o apoio da universidade para auxiliar tais participações visando, pelo menos, o cumprimento da Lei de aquisição de produtos da Agricultura Familiar.

\section{Agradecimentos}

A Pro-reitoria de Extensão (PROEX) da Universidade Federal de São João del Rei - MG pela a bolsa de estudo para projeto contemplado no edital $\mathrm{N}^{\circ} 011 / 2018 / \mathrm{UFSJ} /$ Proex e todo suporte em recursos instrucionais e requisições de transporte para os translados das crianças das escolas até ao Campus Tancredo de Almeida Neves.

Ao Departamento de Zootecnia (DEZOO) pelo apoio para manutenção do Meliponário Didático-experimental e cessão de espaço para realização das reuniões do GEAPIS.

\section{Referências}

Abreu, M. (1995). Alimentação Escolar na América Latina: programas universais ou focalizados/políticas de descentralização. Merenda Escolar. 15(67).

Brasil. Ministério da Educação. Programa Nacional de Alimentação Escolar. https://www.fnde.gov.br/index.php/programas/pnae/pnae-sobre-oprograma/pnae-historico.

Brasil. (2009). Resolução/CD/FNDE no 38 de 16 de julho de 2009. Dispõe sobre o atendimento da alimentação escolar aos alunos da educação básica no Programa Nacional de Alimentação Escolar (PNAE). Diário Oficial da União 2009, 16 jun.

Camargo, J. M. F. \& Moure, J. S. (1996). Meliponini Neotropicais: o gênero Geotrigona Moure, 1943 (Apinae, Apidae, Hymenoptera), com especial referência à filogenia e biogeografia. Arquivos de Zoologia. 95-161.

Camargo, J. M. F. \& Pedro, S. E. M. (2013). Meliponini Lepeletier, 1836. In: Moure, J. S., Urban, D. \& Melo, G. A. R. eds. Catalogue of Bees (Hymenoptera, Apoidea) in the Neotropical Region. Curitiba, Sociedade Brasileira de Entomologia. 272-578.

Castanheira, E. B., \& Contel, E. B. (1995) Isoenzymes related to flight activity in Tetragonisca angustula (Hymenoptera: Apidae: Meliponinae): Evidence of posttranslational modification of the hexokinase and detection of new glycerol-3- phosphate dehydrogenase variants. Biochemical Genetics. 33(11-12), 365375.

Costa, M. M. S. et al. (2012). Proposta de trilha ecológica como atrativo ecoturístico na área de proteção ambiental da barra do Rio Mamanguape - PB. Mossoró. Revista Turismo: estudos e práticas. 104-117.

Gallo, F., Nakano, O., Silveira Neto, S., Carvalho, R. L., Batista, G. C., Gorgatti Neto, L., \& Soares, J. M. (1994). Acerola para exportação: aspectos técnicos da produção. Brasília. MAARASDR-FRUPEX / Embrapa-SPI. 43. 
Research, Society and Development, v. 10, n. 9, e57310918113, 2021

(CC BY 4.0) | ISSN 2525-3409 | DOI: http://dx.doi.org/10.33448/rsd-v10i9.18113

Gallo, D., O. Nakano, S. Silveira Neto, R. L. Carvalho, G. C. de Batista, E. Berti Filho, J. R. Parra, R. A. \& Zucchi, S. B. (1988). Alves \& J. D. Vendramim. Manual de entomologia agrícola. Agronômica Ceres. 649.

Giannini, T. C., Acosta, A. L., Garófalo, C. A., Saraiva, A. M., Alves Dos Santos, I., \& Impeatriz-Fonseca, V. L. (2012). Pollination services at risk: Bee habitats will decrease owing to climate change in Brazil. Ecological Modelling. 244(3), 127-131.

Gruter, C., Karcher, M. H., Ratnieks, F. L. W. (2011). The natural of nest defence in a stingless bee, Tetragonisca angustula (Latreille) (Hymenoptera: Apidae), with two distinct types of entrance guards. Neotropical Entomology. 40(1), 55-61.

Lacerda, L. M., Zucchi, R. \& Zucoloto, F. S. (1991). Colony condition and bionomic alterations in Geotrigona inusitata (Apidae, Meliponinae). Acta Biológica Paranaense. 20(1-4), 109-123.

Lautenbach, S., Seppet, R., Liebscher, J., \& Dormann, C. F. (2012). Spatial and temporal trends of lobal pollination benefit. Plos One. 7(4), 1155-1163.

Lemes, E. O. A., Rodrigues, M., \& Moura. (2004). Criação de três trilhas interpretativas como estratégia em um programa de interpretação ambiental do Parque Estadual do Itacolomi. Relatório do Projeto: UFOP: Ouro Preto.

Ludke, M., \& André, M. E. D. A. (1986). Pesquisa em educação: abordagens qualitativas. EPU, 11.

Nogueira-Neto, (1970). A criação de abelhas indígenas sem ferrão. Chácaras e Quintais. 365.

Nogueira-Neto, (1997). Vida e criação de abelhas indígenas sem ferrão. Nogueirapis.

Ribeiro A. L., Ceratti S, \& Broch D. T. (2013). Programa Nacional de Alimentação Escolar (PNAE) e a participação da agricultura familiar em municípios do Rio Grande do Sul. GEDECON.

Thiollent, M. (2005). Metodologia da pesquisa- ação. (14a ed.), Cortez.

Triches, R., S., \& Schneider, S. (2010). Alimentação Escolar e Agricultura Familiar: reconectando o consumo a produção. Saúde Soc. São Paulo. 19(4), 933945.

Unesco. (2018). A Criança Descobrindo, interpretando e Agindo sobre o Mundo. In: Série Fundo do Milênio para a Primeira Infância. Cadernos Pedagógicos v. 2. UNESCO

Zucchi, R. A., Silveira Netto, S., \& Nakano, O. (1993). Guia de identificação de pragas agrícolas. Piracicaba: FEALQ. 139. 